\title{
O mesmo. O outro. ${ }^{1}$
}

\section{Virginia Ungar ${ }^{2}$}

Quero começar agradecendo por este convite da SBPSP, a seu presidente Bernardo Tanis, que me permite estar outra vez nesta sociedade que tanto amo e onde tenho tantos amigos. Não preciso dizer que me sinto em casa.

O tema que nos convoca hoje é tão convidativo quanto difícil de delimitar e ancorar no eixo psicanalítico.

Tem sido o foco de debates no campo da filosofia há muitos anos, situação reforçada nos pósestruturalistas dos quais somente mencionarei alguns: Foucault, Deleuze, Derrida, Agamben, Levinas e Nancy. Não quero deixar de mencionar Julia Kristeva, quem convidamos para ministrar a conferência de abertura do Congresso da IPA em Londres sobre "O feminino". Voltarei a este tema em breve.

A diferença entre o si mesmo e o outro não é fácil de abordar embora na psicanálise ambos estejam relacionados desde o começo da nossa disciplina. Freud já no Projeto para uma psicologia científica de 1895 explica a vivência de satisfação, que será retomada em 1900 em A interpretação dos sonhos na qual deixa muito clara a dependência total do humano a respeito do cuidador para que lhe proporcione aquilo que não pode realizar: a ação específica.

No fim de semana passado participei do Congresso da Associação Psicanalítica do Uruguai que teve como tema "O desamparo" onde fora possível escutar apresentações muito interessantes. Agora tenho a impressão de assistir uma sorte de continuum, mas também uma

\footnotetext{
${ }^{1}$ Este trabalho é a conferência de abertura do I Simpósio Bienal "O mesmo, o outro: Psicanálise em movimento" da Sociedade Brasileira de Psicanálise de São Paulo.

2 Presidente da IPA - International Psychoanalytical Association
} 
composição coral que não acaba, que sempre - e por sorte- vai continuar inacabada. Como disse Nietzsche "o humano é essencialmente inacabado, é sempre o porvir". Este Simpósio vai continuar produzindo efeitos e deixando caminhos abertos para pensar.

Entrando na especificidade do tema na atualidade e no nosso campo, acho que não há nenhuma dúvida sobre o papel do outro humano na constituição do sujeito, quer dizer que este processo só pode ocorrer na dinâmica de uma construção intersubjetiva.

Estão distantes os tempos em que os desenvolvimentos psicanalíticos podiam concentrar-se naquilo que provinha do paciente sendo a posição do analista a de um decodificador - por exemplo, em um enfoque teórico kleiniano, utilizando sua contratransferência como outra fonte de informação - .

Os desenvolvimentos pós-freudianos avançaram por diferentes linhas. Na divisória de águas sobre a estruturação precoce do psiquismo que surge a partir da análise de crianças muito pequenas, Melanie Klein postula a noção de um mundo interno que vai colorir as percepções sobre a realidade. Desde o início há um eu capaz de estabelecer uma relação com o objeto, mas a meu ver, é apenas em 1946 quando introduz a identificação projetiva que dá lugar à existência de um objeto externo separado do sujeito que vai hospedar as projeções daquilo intolerável para o bebê.

Mais tarde Bion amplia o valor da Identificação Projetiva que chamou de Realista e a apresenta como o mais primitivo modo de comunicação do bebê com sua mãe.

A teoria kleiniana da Inveja, tão controversa e rejeitada, representa para mim uma valiosa contribuição clínica à qual considero chamar teoria kleiniana do narcisismo. É o ataque destrutivo ao objeto de amor e é primária entre outras razões (discutíveis, certamente) porque não precisa de nenhum disparador: acontece com a mera presença do outro que tem algo para dar. O objeto da inveja é, então, essencialmente outro, outro radical, de modo que hoje, 60 
anos depois de sua formulação, poderíamos entender a inveja como a intolerância radical à alteridade.

É depois Meltzer quem em 1988 traz a noção do Conflito Estético e com isto impulsiona a proposta kleiniana, ligada com os desenvolvimentos de Bion. Propõe que o encontro inicial, mítico, com o seio da mãe como representante da beleza do mundo, coloca o bebê de entrada em uma situação de conflito. As emoções colocadas em jogo frente ao impacto da beleza o superam e espantam. A essência do conflito estético é que não existe o impacto da beleza sem o conflito que acontece entre o que pode ser percebido, o exterior belo e o interior, que não é observável, é desconhecido, enigmático, apenas conjecturável e se torna a partir de então fonte atormentadora de toda ansiedade.

A partir desse momento a opção direcionada ao desenvolvimento mental estará dada pela possibilidade de tolerar essa pergunta sem resposta. Quer dizer, ser capaz de suportar a lenta construção da noção do mistério essencial do interior de outra pessoa, que implica a ideia do mistério do mundo.

Claro que há linhas teóricas fundamentais como os desenvolvimentos winnicottianos sobre o espaço transicional como um lugar virtual que só se constitui justamente com a contribuição da mãe e do bebê até o ponto de assegurar que não há criança sem mãe.

Também na teoria lacaniana o lugar do Outro diferenciado do outro se divide entre o grande Outro, tesouro de significantes e o pequeno outro que é um semelhante.

Não poderia sequer mencionar todos os aportes fecundos de autores pós-freudianos sobre este tema, mas gostaria brevemente de referir-me a uma contribuição que abriu espaços para continuar pensando nesta linha, que inauguraram Isidoro Berenstein e Janine Puget ao trabalhar sobre noções como a interferência, o efeito de presença ou o princípio de incerteza, a diferença entre o que eles nomearam a lógica do Um e do Dois e, acima de tudo, a 
importância essencial do espaço virtual entre o Um e o Outro denominado o entre, que é elemento de produção vincular.

Daqui nasce um desenvolvimento fecundo latino-americano que se espalha pelo mundo sobre a possibilidade de trabalhar no que se denominam as configurações vinculares.

Como um dos eixos deste encontro propuseram o mal-estar na clínica e me parece uma excelente oportunidade para revisitar o artigo de Freud "O mal-estar na cultura" de 1930, 88 anos depois. Entre esse momento da história e a atualidade, houveram mudanças impactantes na cultura.

Freud justamente começa o artigo de 1930 referindo-se ao sentimento oceânico, esse de "ligadura indissolúvel" de "co-pertinência com o mundo exterior" e o refere à religião como uma ilusão - e ao estado de paixão no qual diz "os limites entre o eu e o objeto ameaçam desaparecer". Retomando a ideia do sentimento oceânico - o ser um com um todo e sua relação com a fase precoce do sentimento egóico, Freud, como sabemos, postula que as necessidades religiosas derivam do desamparo infantil e a saudade da proteção do pai que perdura.

Diz, também, que o propósito humano de alcançar a felicidade é irrealizável e que, em troca, o sofrimento ameaça desde distintas áreas: o corpo, o mundo exterior, os vínculos com outros seres humanos e a satisfação pulsional que pode causar tanto felicidade, como sofrimento.

Para Freud a cultura serve a dois fins: "a proteção do ser humano frente à natureza e a regulação dos vínculos recíprocos entre os homens". Este último ponto se vê reforçado na afirmação de que a convivência humana só se torna possível quando se aglutina uma maioria mais forte que os indivíduos isolados, e coesa frente a estes. E segue com a afirmação de que o poder desta comunidade se contrapõe, como 'direito', ao poder do indivíduo, que é condenado como 'violência bruta'. Ou seja, a substituição do poder do indivíduo pelo da 
comunidade é o salto cultural decisivo. Depois a lei passará a regular esta convivência que tem como base o sacrifício pulsional com o qual os indivíduos contribuem para a comunidade de maneira que "ninguém pode ser vítima da violência bruta" (Freud, 1930/1976).

Neste ponto deixo o artigo para trazer brevemente alguns pontos para o intercâmbio e a discussão.

O primeiro tem a ver com que precisamos voltar a Freud, mas também devemos permitir-nos fazer uma leitura contemporânea. Neste sentido, na cultura deste momento quem sabe não se trate da renúncia pulsional, e sim de um convite ao contrário.

Para isto, me apoio na leitura de um ensaio de um jovem historiador, Pablo Hupert (2016) que se chama "O bem-estar na cultura e outras composições precárias". Começa propondo que hoje em dia o mal estar no social mutou para bem-estar na cultura. E a partir daí a proposta freudiana do mal estar gerado pelas restrições que a cultura impõe ao indivíduo em prol da vida em sociedade fica questionada. A problemática indivíduo-sociedade se torna obsoleta na cultura que promete bem estar ao sujeito. Também propõe que assim como o malestar na cultura limita o indivíduo, o bem- estar o ilimita. Nos tempos sólidos de Freud o indivíduo era limitado pela cultura para armar a comunidade. Agora, o bem estar se "vende" como acessível com só um click de qualquer dos dispositivos com os quais contamos.

Por outro lado, a proposta freudiana de que a cultura regula os vínculos recíprocos entre os homens parece ao menos, interrogada, nesta época em que justamente estes vínculos não parecem poder regular-se, é mais bem a desvinculação que parece estar no eixo contemporâneo.

E então nos perguntamos: por um lado este desligamento, esse isolamento narcísico da sociedade atual, esse prometido bem estar que não é felicidade, deve ser gozo - para explicar isto a meus colegas lacanianos - Terá algo a ver com a proposta freudiana que de alguma 
forma condenava o poder do indivíduo que não ficava ligado pela cultura como o portador da violência bruta?

E aqui vem o analista desconcertado, o mal-estar na clínica. O contexto do mal-estar social em que vivemos em todo o mundo se vive na clínica cotidiana e muito mais nos lugares em que os jovens profissionais trabalham em esferas da saúde pública.

Hoje em dia parece que é muito difícil lidar com a alteridade, com o diferente. Como dissemos recentemente, o eixo da sociedade contemporânea parece estar ancorado em amarse e dar-se bem estar a si mesmo. E odiar e rejeitar o diferente, senão, é difícil de entender a direção que o mundo inteiro está tomando. E as mudanças se dão a uma velocidade vertiginosa, mais rápido do que podemos apreender. Diz a Rainha Vermelha, de Alice através do espelho: "corra, se ficar parada vai para trás".

Nessa rejeição ao diferente (seja gênero, classe social, cor da pele, religião, país de origem ou outros) se aninha o germe do violento. Teria isto relação com a violência bruta daquele que não faz parte da comunidade?

De todos os mal-estares atuais gostaria de centrar-me na violência contra a mulher. É um tema que nos interpela de maneira triste e trágica. Nem preciso dizer que como profissionais da saúde mental não podemos deixar de expressar nossa forte oposição a qualquer tipo de discriminação, de opressão e de não reconhecimento da alteridade. $O$ fato de que tenha se tornado visível e que o tema do feminicídio tenha unido tantas vozes desde diversos âmbitos mostra que a mulher não quer aparecer mais como a vítima, mas como quem toma a questão em suas mãos e levanta uma consigna como "vivas nos queremos" de uma maneira sempre criativa (a greve, vestir-se de preto, a mobilização). Embora há milênios arrastemos o tema do maltrato e a não igualdade de direitos e oportunidades, chegou o momento de torná-lo visível e de tentar também semear consciência. "Nem uma a menos" nasceu como um grito coletivo e estremecedor na Argentina no dia 3 de junho de 2015 e continuou crescendo e expandindo-se no mundo. 
Atualmente, precisamente neste ano, na Argentina, surgiu outro lugar de reapropriação do espaço de dissidência, outro cenário enorme no campo social onde as individualidades desagregadas voltam a se unificar desde as particularidades e tentam repensar a condição da mulher em nossa cultura: os debates no Congresso e no Senado da Nação em relação à despenalização do aborto. No Congresso alcançou a média sanção da lei, no Senado não conseguiu ser aprovada, mas com uma acirrada diferença contra. Mobilizaram-se milhões de mulheres (no dia 13 de junho um milhão, diz-se que dois milhões no 8 de agosto) que se reuniram pacificamente nas ruas e em uma vigília noturna em duas tardes e noites geladas e com chuva.

Embora a tecnologia e as redes sociais possam de alguma maneira ser imputadas como causa de certo mal estar ao perder as fronteiras da intimidade, as redes sociais sustentaram e sustentam o grito coletivo.

Agora, passo a outro tema que está relacionado e que me faz pensar sobre temas que, devo confessar, não costumo pensar. Mas este exercício me parece interessante.

Ter sido votada como presidente da IPA me coloca em uma situação institucional nova. E por isso mesmo, entendo como oportuno e necessário interrogar-me sobre o que implica conduzir uma instituição em geral e particularmente a IPA hoje, em uma época como a nossa que, como todas, tem seus problemas e desafios. Quando fui eleita para ocupar este cargo, me surpreendeu o impacto que gerou - pela primeira vez - uma mulher ser eleita para conduzir esta associação fundada em 1910, impacto que quem sabe tenha sido mais notável fora do que dentro da IPA. Em entrevistas, em jornais e na TV, me perguntaram por que eu achava que até agora a IPA não tivera uma mulher como presidente. E respondi mais ou menos a mesma coisa frente a estas perguntas. Embora não seja simples ensaiar uma resposta geral, não pude deixar de considerar a lógica dominante nas sociedades e nas configurações familiares modernas nas quais o homem era o eixo e o centro da vida pública. Então, a divisão sexual do trabalho familiar estabelecia que a atividade política, institucional e pública era território (quase exclusivo) dos homens e ainda mais a condução ou a direção desses territórios. Desta forma, para os códigos hegemônicos da época vitoriana, era impensável que 
uma mulher conduzisse uma instituição, especialmente a IPA. Como imaginam, teria fugido da regra geral.

Colocado assim, a necessidade de uma perspectiva de gênero para esta análise fica evidente.

Não é possível pensar na condução tal como foi entendida nos albores da teoria freudiana, esta variação de contexto e subjetividade é uma condição de época que excede abertamente as instituições psi.

É necessário pensar e repensar a condução de nossas instituições. E quando o fazemos desde a condução de uma instituição, nos encontramos com o que destaquei antes: não fomos formados para esta tarefa. Nossa formação tem como eixo a intervenção clínica no consultório que, por outro lado, coincide com a representação socialmente instalada do analista como terapeuta de consultório privado. Em um mundo de mudanças constantes como o nosso, além de repensar a clínica à luz das variações na subjetividade e nas formas de sofrimento, é necessário ensinar uma Psicanálise capaz de intervir em novos cenários, no consultório privado, mas também além dele.

Quando assumimos com Sérgio Nick, faz pouco mais de um ano, dissemos que o consultório é um dos territórios da Psicanálise, mas não é o único.

Quem sabe em uma suposta época "dourada" ou do boom da psicanálise em que havia listas de espera de anos para conseguir um analista, era suficiente refugiar-se nos consultórios. Mas estamos em outra etapa. Agora, se pretendemos (e eu pretendo) que a psicanálise perdure e produza novos efeitos, na cultura deve fertilizar-se em intercâmbios com outras disciplinas e em outros âmbitos.

Dito isto, retomemos algumas interrogações em torno da perspectiva de gênero. Em primeiro lugar, se nos pergunta se existem particularidades em relação ao gênero quando se trata de conduzir. Foi dito e escrito muito a respeito disso. 
Partamos de uma evidência: nossa época não é a de princípios do século passado quando nasceu a psicanálise. Tampouco a situação das mulheres que estamos aqui é representativa da maioria das mulheres. É verdade que antes houve outras mulheres no lugar de condução de muitas sociedades psicanalíticas.

Isto não quer dizer que vamos negar o lugar vulnerável que tem tido e ainda tem a mulher em nossa sociedade. Sem ir muito longe, que recebe menos salário pelo mesmo trabalho e qualificação, que tenha menos possibilidade de aceder a posições estratégicas e de condução, o que a "mentalidade machista" se espalhe em nossos consultórios também e muitas vezes com mais força desde uma mulher. Este último não deixa de surpreender-me e o observo muito e também em pacientes jovens.

Não vou avançar nesta análise, mas, antes de terminar, me interessa destacar duas questões: desde 1998, a IPA conta com um comitê (COWAP) que produziu trabalhos científicos muito sérios e prestigiosos e encontros científicos de relevância.

Em segundo lugar, como vocês devem saber, criamos uma nova estrutura na IPA denominada IPA na Comunidade com a ideia de levar adiante uma tarefa que na América Latina tem história e tradição: a de sair de nossos consultórios e sociedades e ir pessoalmente ao encontro dos jovens profissionais para oferecer nosso ponto de vista desde a Psicanálise.

Esta nova estrutura tem cinco comitês: IPA na Educação, na Saúde, comitê de Violência, Psicanálise e Lei e IPA na Cultura. Dentro há subcomitês entre eles, ressalto apenas alguns como: adições, nexos com a Psiquiatria, transtornos alimentares e, muito especialmente, Migrações e Refugiados. Este é o ponto mais incandescente em nossos dias e onde se concretiza a intolerância à alteridade. Não vou entrar em detalhes para explicar o porquê da criação deste espaço na IPA. Em termos de Agamben, um dos pensadores mais lúcidos e prolíficos de nosso tempo, ao referir-se aos estados de exceção sustenta que esse estado primordial no qual se tende a que a própria vida se associe ao poder ilimitado é o verdadeiro nomos de nosso tempo, e sustenta essa afirmação com a descrição dos inumeráveis estados de 
sitio que se declaram, os estados de "emergência" que se proclamam e os decretos de necessidade e urgência que se ditam são ressurgências desses (os estados de exceção).

Em segundo lugar e para concluir, me atrevo a dizer que nossa geração, ao menos no terreno $p s i$, que foi atravessada e por isso constituída por intensas mudanças em diversos âmbitos, se enfrenta com uma série de interrogações. Entre outras, voltar a pensar a vida institucional e a vida pública. Celebro que este encontro contribua para a construção dessa geração, desse futuro, que ainda está em formação.

\section{Referências}

Agamben, G. (2004). Estado de excepción. Buenos Aires, Adriana Hidalgo editorial .(trabalho original publicado em 2003).

Bion, W.R. (1977). Una teoría del pensamiento, en Volviendo a pensar. Buenos Aires, Horme ediciones. (trabalho original publicado em 1962)

Freud, S. (1976). Proyecto de una psicología para neurólogos. Vol. I, Buenos Aires, Amorrortu. (trabalho original publicado em 1895)

Freud, S. (1976). La interpretación de los sueños. Vol. IV, Buenos Aires, Amorrortu. (trabalho original publicado em 1900)

Freud, S. (1976). El malestar en la cultura. Vol. XXI, Buenos Aires, Amorrortu. (trabalho original publicado em 1930)

Klein, M. (1980). "Notes on some schizoid mechanisms". In The Writings of Melanie Klein. Vol. III, London,Hogarth. (trabalho original publicado em 1946)

Hupert, P. (2016). El bienestar y otras composiciones precárias. Buenos Aires, editorial Pie de los hechos. (trabalho original publicado em 2012)

Meltzer, D. (1988). The Aprehension of Beauty. London, Clunie Press. Tradução: Dante Rovere 